\title{
Application of Fuzzy Control with Market-Based Control Strategy to Structures
}

\author{
Gang Li, ${ }^{1}$ Hong-Nan $\mathrm{Li}^{2}{ }^{2}$ and Qi-Feng Liu ${ }^{1}$ \\ ${ }^{1}$ Faculty of Infrastructure Engineering, Dalian University of Technology, Institute of Earthquake Engineering, Dalian, \\ Liaoning 116024, China \\ ${ }^{2}$ Faculty of Infrastructure Engineering, Dalian University of Technology, Dalian, Liaoning 116024, China
}

Correspondence should be addressed to Gang Li; gli@dlut.edu.cn

Received 21 April 2013; Accepted 7 July 2013

Academic Editor: Gang-Bing Song

Copyright (C) 2013 Gang Li et al. This is an open access article distributed under the Creative Commons Attribution License, which permits unrestricted use, distribution, and reproduction in any medium, provided the original work is properly cited.

\begin{abstract}
The market-based control as a control strategy is developed based on an analogy between the control force-energy source in the structural area and the supply demand in the free market. The optimal problem of control force from an actuator is transformed to that of the allocation resource in the market. Since the supply-demand relation model and iteration procedure for the optimal price solution are necessary and relatively hard to understand and perform for civil engineers, the fuzzy logical method is proposed in the framework of the market-based control to acquire an equivalent system corresponding to the market-based control method. An equivalent fuzzy logical rule is established through analyzing a single-degree-of-freedom system with the controller using the MBC strategy under earthquakes. The results show that the fuzzy logical method is able to also reduce the displacement and acceleration responses effectively similar to the MBC method, and the consumed computational time for the fuzzy logical method is obviously saved.
\end{abstract}

\section{Introduction}

At present, the structural control technique is verified as an effective way to reduce responses of structures under natural hazards such as earthquakes and strong winds. Over past few years, a number of structural control strategies have been developed and applied in practices, specifically in seismic regions. Structural control systems, in general, fall into four categories: passive, active, semiactive, and hybrid control based on whether the power source is necessary. For the active and semiactive control technique, the control force is often determined by control strategies. Conventional control strategies include the linear quadratic regulator (LQR), modal control, smart control, and $\mathrm{H} 2$ and $\mathrm{H} \infty$ [13]. The market-based control (MBC) as a multiobjective distributed control approach achieves the optimal allocation of the control energy and determines the controlling force by modeling seller and buyer behaviors in the free-market area. The optimal problem of control force from the actuator in the structural control area is then transformed to that of allocation resources in the market. Since the MBC concept was proposed by Clearwater [4], it had been developed and applied in many fields, such as the telecommunication, mechanism, and mission plan [5-9]. Lynch and Law [10] firstly applied the MBC method in civil engineering and subsequently presented a market-based energy control method. $\mathrm{Huo}$ and $\mathrm{Li}[11]$ incorporated the $\mathrm{MBC}$ in the tuned liquid column damper for reducing structural responses. Li [12] developed supply-demand relations and further improved control effectiveness. In addition, Li et al. [13] presented a way to compress the computation time for the nonlinear analysis of the structure through combining the $\mathrm{MBC}$ and the force analogy method.

After stepping into the 21st century, more and more works were focused on the implementation of the artificial intelligent algorithm in the structural control. The fuzzy logical method (FLM), as an intelligent algorithm, was incorporated in the structural control and developed in few years ago. Advantages of the FLM are effective and easy in handing nonlinearities, uncertainties, and heuristic knowledge when 
it was applied in the active and semiactive control. Aldawod et al. [14] designed a multiobjective optimal fuzzy logic controller for seismically excited building structures and verified its inherent robustness and ability to handle nonlinearities and uncertainties in the structural behavior and loading. Ahlawat and Ramaswamy [15] applied the FLM for the active vibration control of tall buildings. Schurter and Roschke [16] used a neurofuzzy technique to control a single-degreeof-freedom and four-degrees-of-freedom building models. Park et al. [17] presented an independent modal space fuzzy control technique for the vibration control of earthquakeexcited structures. The technique adopts a two-step design procedure consisting of designing an optimal controller in the modal space and fuzzy tuning of predesigned modal control gains. Bhardwaj and Datta [18] presented a methodology for the semiactive control of building frames using multiple semiactive hydraulic dampers driven by fuzzy controllers. The results of study showed that an efficient semiactive control strategy was developed using a fuzzy rule base. Kim and Roschke [19] validate the advantage of fuzzy logic approach on handling the nonlinear behavior of the system. Guclu and Yazici [20] investigated the effectiveness of a supervisory fuzzy control technique for the reduction of seismic response of a smart base isolation system. Zahrai and Shafieezadeh [21] designed a fuzzy logic based controller and used it to reduce vibrations of a tall building under cross-wind excitations. The results verified the superior performance of the semiactive fuzzy controller over the passive controller in response to mitigation of the perturbed structure. Zhao and Li [22] carried out a shaking table test of seismic response reduction of semiactive fuzzy control system including a new type of piezoelectric variable-friction damper and fuzzy controller. Yeh [23] developed an adaptive fuzzy sliding model control based Lyapunov theory and got a satisfactory result in the application of structural control for buildings with sliding bearing isolators.

The MBC has a distinct advantage when it is applied in a large complex structure, because it as a large unity consists of many markets so that it is capable of performing a decentralized control through dividing the large complex structure into several substructures and establishing corresponding relations among the substructures. However, the controlling effect for all substructures is determined by the supplydemand relation of markets, and the equilibrium price of the commodity is formed depending on its own supply-demand relation and the price tendency. The presence of numerous supply-demand relation models and iteration procedures for the optimal price solution is necessary and relatively hard to understand and perform for civil engineers, so that it makes the application of the MBC in this kind of structures more sophisticated. The FLM is incorporated in the framework of the MBC to acquire an equivalent system corresponding to the market-based control method in this study. The objective of present study is to simplify the process of the $\mathrm{MBC}$ and improve its robustness and uncertainty through incorporating the FLM into the structural vibration control procedure. An equivalent fuzzy rule is established through analyzing a single-degree-of-freedom (SDOF) system with the controller using the MBC strategy under earthquakes.
The robustness and uncertainty of the FLM are validated by its application in a multidegrees-of-freedoms structure under different earthquakes.

\section{Fundamental Background}

2.1. Framework of $M B C$. The governing equation of motion for an SDOF system with controller can be expressed as

$$
m \ddot{x}(t)+c \dot{x}(t)+k x(t)=-F(t)+U(t),
$$

where $x(t), \dot{x}(t)$, and $\ddot{x}(t)$ represent the displacement, velocity, and acceleration of the SDOF system, respectively; $m$ and $k$ are the system mass and stiffness; $c$ denotes the viscous damping coefficient; $U(t)$ is the controlling force from the actuator, and $F(t)$ is the environmental load.

The MBC as a control algorithm can realize the structural vibration control through the analogy between the free market and structural control system. In the free market, the demand function $J_{D}$ is determined by its energy consumption $Q_{D}$, energy price $p$, and dynamical responses $Y(t)$; the sellers' supply function $J_{S}$ is determined by its own original energy $Q_{S}$ and energy price $p$. Buyers and sellers both pursue their maximum interests at any time. This process has to be restricted by commodity quantities $Q_{\max }$ and virtual wealth $W_{\max }$. Thus, the relation among these parameters is satisfied by

$$
\begin{gathered}
\max J_{S}\left(Q_{S, p}\right) \quad Q_{S} \leq Q_{\max } \\
\max J_{D}\left(Q_{D 1}, p, Y(t)\right) \quad p \cdot Q_{D} \leq W_{\max }
\end{gathered}
$$

Actually, the supply-demand relation is a core of the overall MBC theory. In the prior research, classical mathematical models have been presented, such as the linear-supply and linear-demand model [12], linear-supply and power-demand model, advanced linear-supply and power-demand model, and linear-supply and exponential-demand model [10]. As a classic model, the linear-supply and linear-demand relation reflects changes of the supply and demand in free market. The price is not obviously linear with the demand in markets, so the advanced linear-supply and power-demand and exponential-demand models were established and validated to be more accurate models. The fundamental framework of the MBC in the structural control has been presented in detail by Lynch and Law [10], so only a short summary based on the linear-supply and power-demand model (ALPM) is provided here as background.

The supply function is written as

$$
Q_{S}=\eta \cdot p(t)
$$

And the demand function is chosen to depict the relation of the demand and price as

$$
Q_{D}=\frac{W(t)|\alpha x(t)+\beta \dot{x}(t)|}{p(t)},
$$

where $\eta$ is the parameter that reflects the energy supply, and $\alpha$ and $\beta$ are the weighting coefficients. 


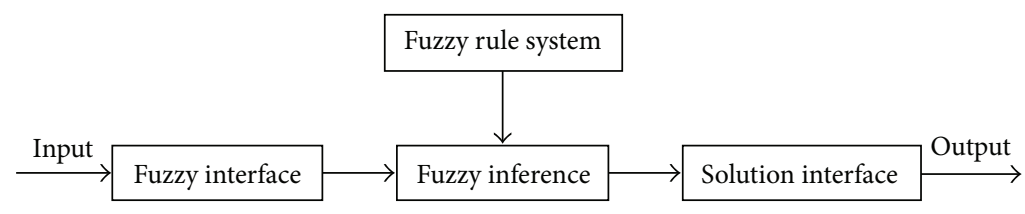

Figure 1: Fuzzy logical system.

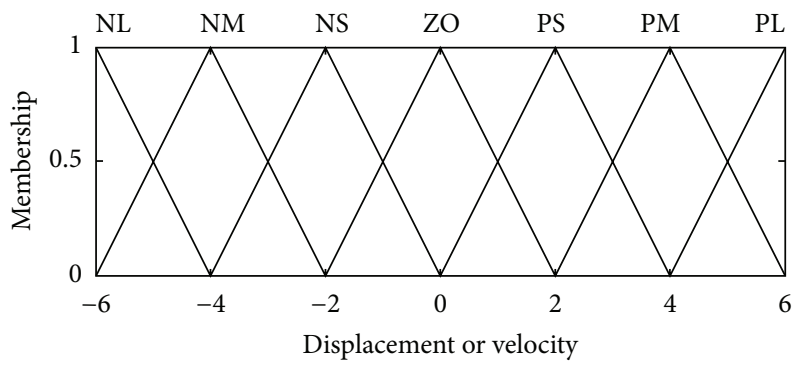

(a)

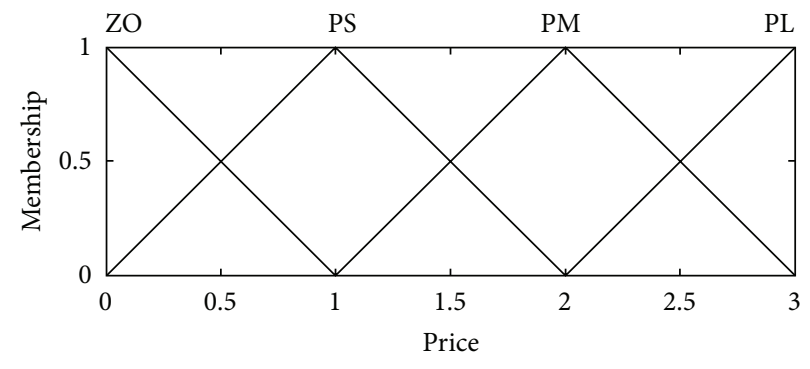

(b)

FIGURE 2: Relations of the membership and variables: (a) displacement or velocity; (b) price.

In the free market, there is a general equilibrium rule between the supply and demand. The rule can be expressed as

$$
Q_{S}=Q_{D}
$$

Substituting (3) and (4) into (5), an equilibrium price is obtained through the resolution of (5) at any time step. The solution of (5) is called the Pareto optimal solution in economics [10]. Then, the control force is written as

$$
U(t)=-K \cdot \frac{W(t) \cdot(\alpha x(t)+\beta \dot{x}(t))}{p(t)},
$$

where $K$ is the gain coefficient related to the actuator. Substituting (6) into (1), the MBC in the structural control is implemented.

2.2. Fuzzy Logical Method. The FLM is capability to simplify the complex relation through mapping of only inputoutput information. The core of structural control is how to determine the controlling force through structural responses, such as displacement and velocity. This process is relatively complex and hard to solve. The controlling force in $\mathrm{MBC}$ is simulated to the price in market, so the structural displacement and velocity are selected as input variables to the fuzzy controller, and the output variable is defined as the price in the free market in this study, as shown in Figure 1. The whole price determination process is replaced by the fuzzy rule simplified through the FLC. The membership function for these three variables is selected as triangle with $50 \%$ overlap (Figure 2). The labels NL, NM, NS, ZO, PS, PM, and PL refer to the linguistic values: negative large, negative medium, negative small, zero, positive small, positive medium, and positive large, respectively.

Although the $\mathrm{MBC}$ mentioned in previous section is clear and simple, the presence of many supply-demand relations leads to an expensive computation in time and makes the MBC strategy complex. In this study, an equivalent control system based on the FLM is developed to represent overall MBC solution process by using the unknown part of the system dynamics and the fuzzy learning model. The relation of the price, displacement $x$, and velocity $\dot{x}_{d}$ can be written as

$$
p(k)=R(x(k), \dot{x}(k)),
$$

where $k$ is the time at sampling; $R$ represents the function of the fuzzy function.

\section{Equivalent Fuzzy Price Rule}

For illustration, a single-degree-of-freedom (SDOF) system, whose mass, stiffness, and damping ratios are $2.25 \times 10^{6} \mathrm{~kg}$, $1.4 \times 10^{7} \mathrm{~N} / \mathrm{m}$, and 0.05 , respectively, is excited by the El Centro north-south ground acceleration record from the 1940 Imperial Valley Earthquake. In order to obtain an equivalent fuzzy price rule to replace the $\mathrm{MBC}$ solution process, the dynamical response analysis of the SDOF structure with the controller based on the method presented in Section 2.2 was carried out. The three-dimensional relations of the price, displacement, and velocity are shown in Figure 3(a), and the fuzzy price rule is obtained and listed in Table 1 . The rule surface that corresponds to the rule bases in Table 1 is generated as shown in Figure 3(b).

The whole process of the MBC in the structural control including the supply-demand relation and price solution is avoided, and much computational time is saved due to the establishment of price rule. It also can be found in Figure 4. In prior researches, the conclusion is that structural parameters and environmental loads have limited influence on the fuzzy rule. It also means that although the FLM is sourced from the SDOF under the given earthquake record, it is universal and will be verified in the next section. 


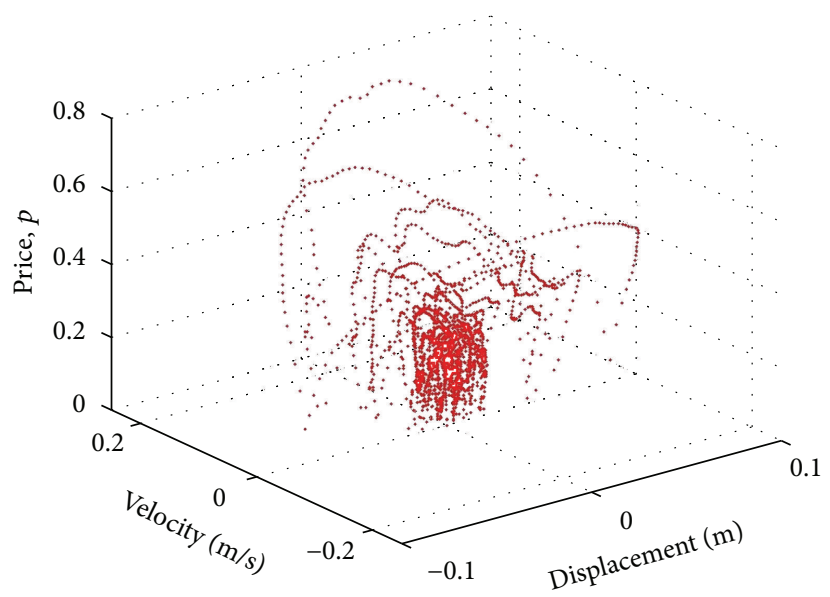

(a)

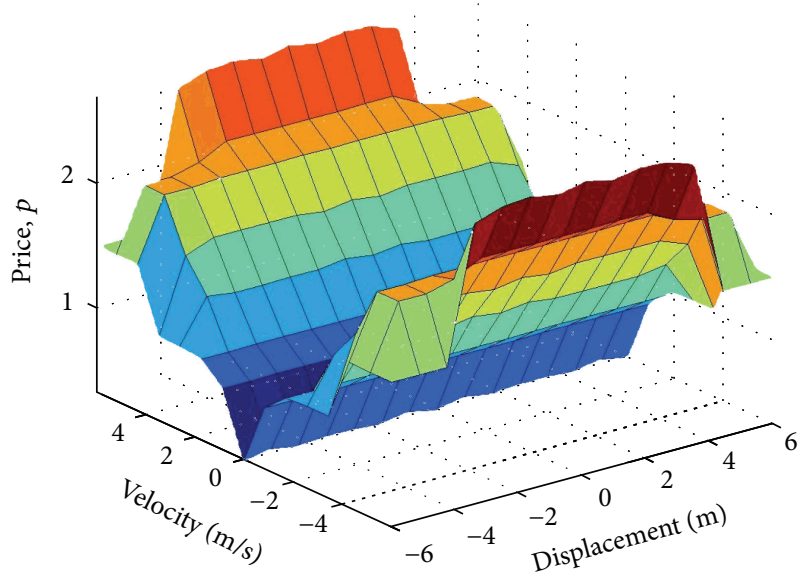

(b)

FIGURE 3: Three-dimensional graphic of the displacement, velocity, and price under El Centro earthquake: (a) the dotted graphic; (b) rule surface graphic.

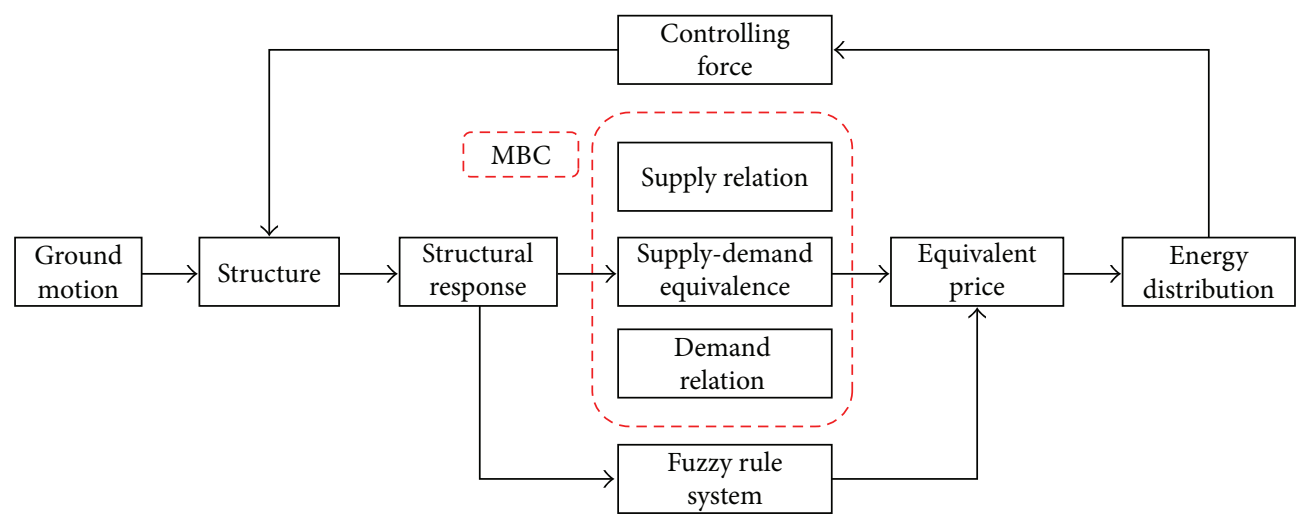

FIgURe 4: Procedure of the MBC and FLM.

TABLE 1: Fuzzy price rule.

\begin{tabular}{lccccccc}
\hline \multirow{2}{*}{ Velocity } & \multicolumn{7}{c}{ Displacement } \\
& NB & NM & NS & ZO & PS & PM & PB \\
\hline NB & $/$ & $/$ & PB & PB & PB & $/$ & $/$ \\
NM & $/$ & PM & PM & PM & PM & PM & $/$ \\
NS & PS & PS & PS & PS & PS & PS & PS \\
ZO & ZO & ZO & ZO & ZO & ZO & ZO & ZO \\
PS & PS & PS & PS & PS & PS & PS & PS \\
PM & $/$ & PM & PM & PM & PM & PM & $/$ \\
PB & $/$ & $/$ & PB & PB & PB & $/$ & $/$ \\
\hline
\end{tabular}

Note: / means no rules in the case.

\section{Application of the Fuzzy Control Method in the MDOF System}

To validate the performance of the FLM established in the previous section, it is applied in a ten-story framed structure, whose parameters are shown in Table 2. In addition, three various earthquake records, which were scaled by various adjusted factors to $0.22 \mathrm{~g}$, are listed in Table 3 and selected
TABle 2: Parameters of the ten-story structure.

\begin{tabular}{lcccccccccc}
\hline Floor & 1 & 2 & 3 & 4 & 5 & 6 & 7 & 8 & 9 & 10 \\
\hline $\begin{array}{l}\text { Mass } \\
\left(10^{3} \mathrm{~kg}\right)\end{array}$ & 980 & 980 & 980 & 980 & 980 & 980 & 980 & 980 & 980 & 980 \\
$\begin{array}{l}\text { Stiffness } \\
\left(10^{6} \mathrm{~N} / \mathrm{m}\right)\end{array}$ & 1819 & 1804 & 1774 & 1659 & 1559 & 1415 & 1728 & 1203 & 881.6 & 881.6 \\
\hline
\end{tabular}

TABLE 3: Earthquake records.

\begin{tabular}{lcc}
\hline $\begin{array}{l}\text { Serial } \\
\text { number }\end{array}$ & Station & Earthquake \\
\hline 1 & El Centro & Imperial Valley (18/5/1940) \\
2 & 0453 Taft Lincoln School & Kern County (21/7/1952) \\
3 & 1028 Hollister City Hall & Hollister 1961/04/09 \\
\hline
\end{tabular}

as inputting loads to verify the robustness of the FLM under different environmental loads. Three cases, which are the structure without control (FREE), with control based on the $\mathrm{MBC}$, and with control based on the FLM, are conclude in this study to verify the effectiveness of the FLM. 


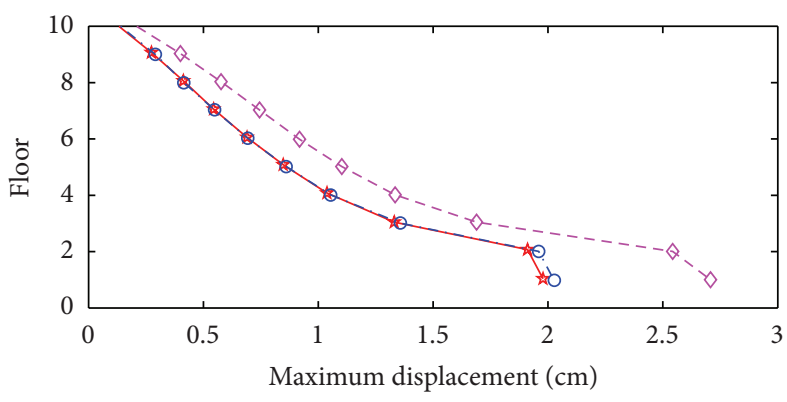

(a)

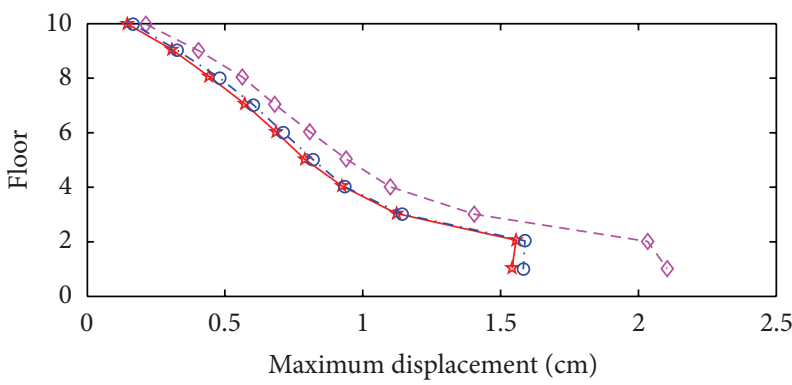

(c)

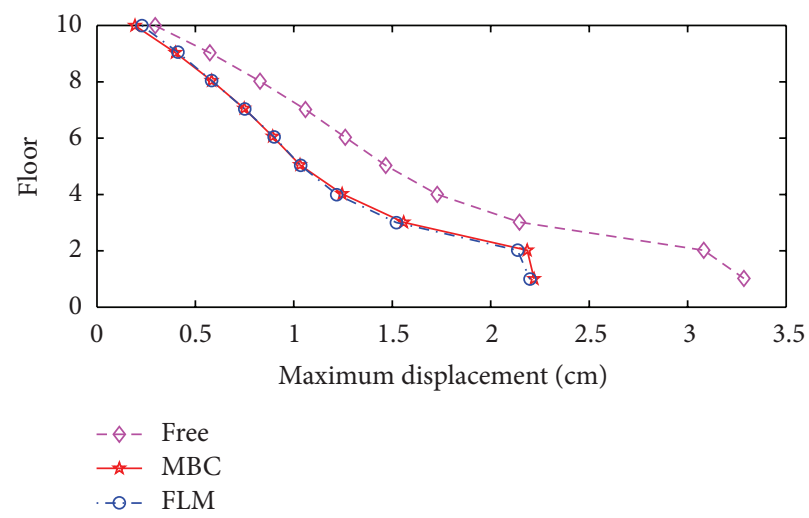

(e)

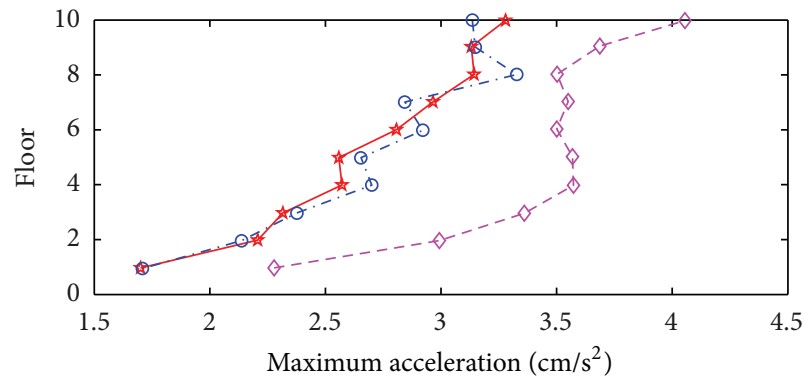

(b)

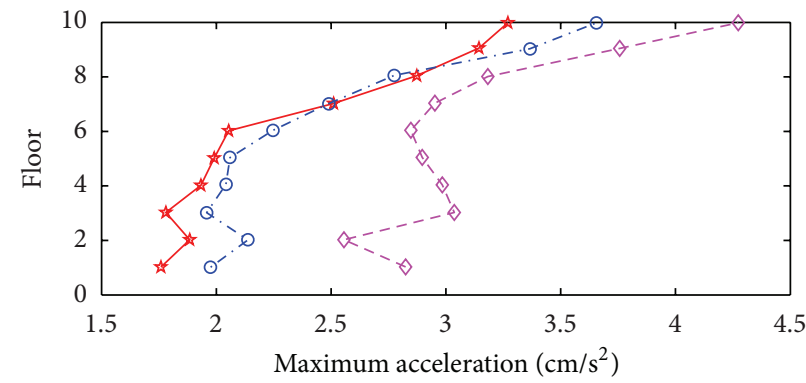

(d)

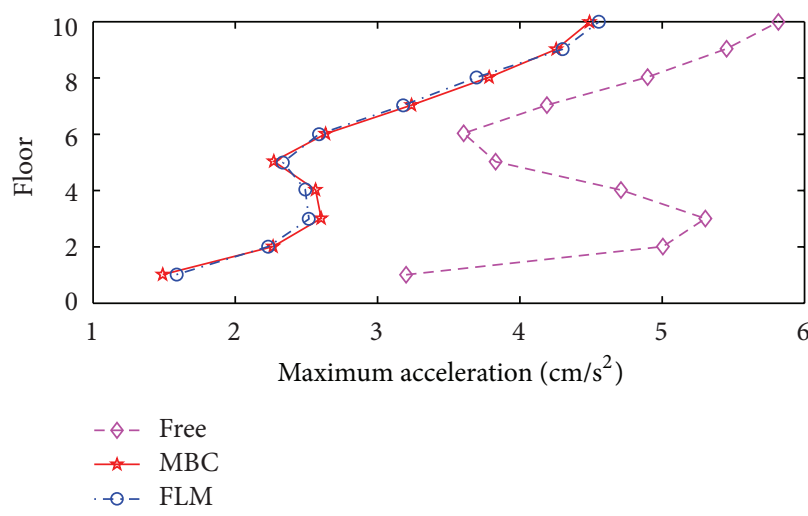

(f)

FIGURE 5: Maximum displacement and acceleration responses of each story under various earthquakes: (a), (c), and (e) maximum displacement under nos. 1, 2, and 3 earthquakes; (b), (d), and (f) maximum acceleration under nos. 1, 2, and 3 earthquakes.

TABLE 4: Comparison of computational time of the FLM and MBC algorithms (unit: second).

\begin{tabular}{lccc}
\hline \multirow{2}{*}{ Methods } & \multicolumn{3}{c}{ Serial number of earthquakes } \\
& 1 & 2 & 3 \\
\hline FLM & 6.8 & 7.0 & 6.7 \\
MBC & 12.8 & 12.4 & 12.8 \\
\hline
\end{tabular}

The comparison of the time consumed on the completion of dynamic control analysis between using the MBC and FLM is shown in Table 4. It can be seen that the FLM compared to $\mathrm{MBC}$ can dramatically reduce the computational time.

The maximum displacement and acceleration of each floor for the three cases, FREE, MBC, and FLM, are shown in Figure 5. It can be seen that the FLM has ability of reducing the displacement and acceleration responses effectively similar to the MBC through comparing responses of these three cases. Table 5 showed the maximum displacement and acceleration responses of the first, fifth, and tenth floor, and the maximum displacement and acceleration reduction ratio attaches to $33.12 \%$ and $50.42 \%$. The controlling force in MBC is simulated to the price in market and also influenced by input earthquakes acceleration. Thus, both the price and input earthquake acceleration should have close changing trend. Figures 6, 7, and 8 illustrated that the price has the same changing trend as the theoretical control force of the first floor under the three earthquake records. The price and theoretical control force in the MBC agree well with that in the FLM. In addition, it was revealed that the FLM has excellent control effectiveness under the three earthquake records although it 
TABLE 5: Peak response and control effect of the structure.

\begin{tabular}{|c|c|c|c|c|c|c|c|}
\hline \multirow{3}{*}{ Earthquakes } & \multirow{3}{*}{ Floor } & \multicolumn{3}{|c|}{ Interstory displacement } & \multicolumn{3}{|c|}{ Inter-story acceleration } \\
\hline & & \multicolumn{2}{|c|}{ Peak $(\mathrm{cm})$} & \multirow{2}{*}{ Reduction ratio (\%) } & \multicolumn{2}{|c|}{ Peak $\left(\mathrm{m} / \mathrm{s}^{2}\right)$} & \multirow{2}{*}{ Reduction ratio (\%) } \\
\hline & & FREE & FLM & & FREE & FLM & \\
\hline \multirow{3}{*}{1} & 1 & 2.71 & 2.02 & 25.37 & 2.28 & 1.71 & 24.90 \\
\hline & 5 & 1.10 & 0.86 & 22.03 & 3.58 & 2.66 & 25.46 \\
\hline & 10 & 0.21 & 0.14 & 33.00 & 4.06 & 3.14 & 22.62 \\
\hline \multirow{3}{*}{2} & 1 & 2.11 & 1.58 & 24.79 & 2.83 & 1.98 & 30.08 \\
\hline & 5 & 0.94 & 0.82 & 12.82 & 2.90 & 2.06 & 29.01 \\
\hline & 10 & 0.22 & 0.17 & 22.45 & 4.28 & 3.66 & 14.47 \\
\hline \multirow{3}{*}{3} & 1 & 3.29 & 2.19 & 33.12 & 3.21 & 1.59 & 50.42 \\
\hline & 5 & 1.47 & 1.03 & 29.64 & 3.83 & 2.33 & 39.10 \\
\hline & 10 & 0.30 & 0.23 & 24.52 & 5.82 & 4.56 & 21.74 \\
\hline
\end{tabular}

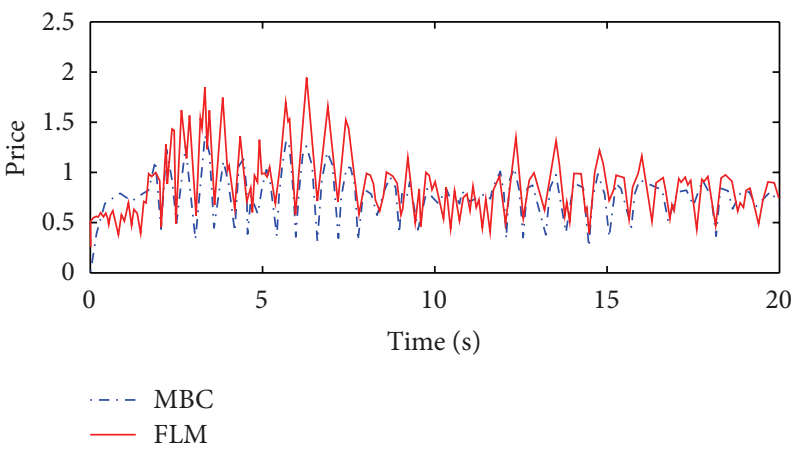

(a)

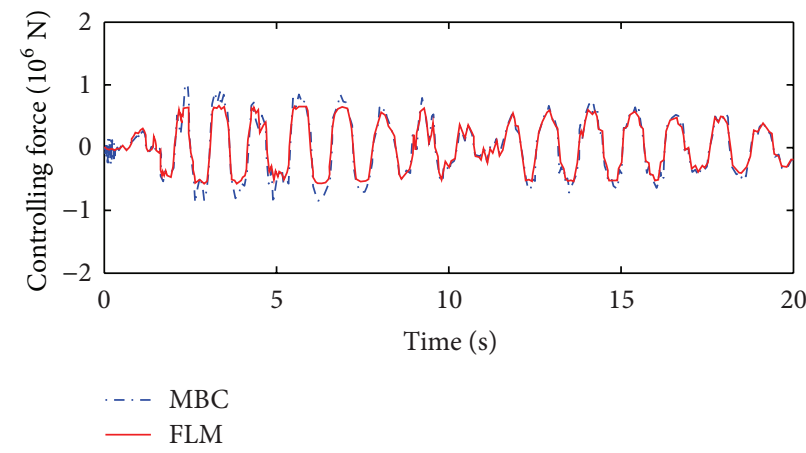

(b)

FIGURE 6: Responses of the structure under no. 1 earthquake record: (a) price time history; (b) control force time history.

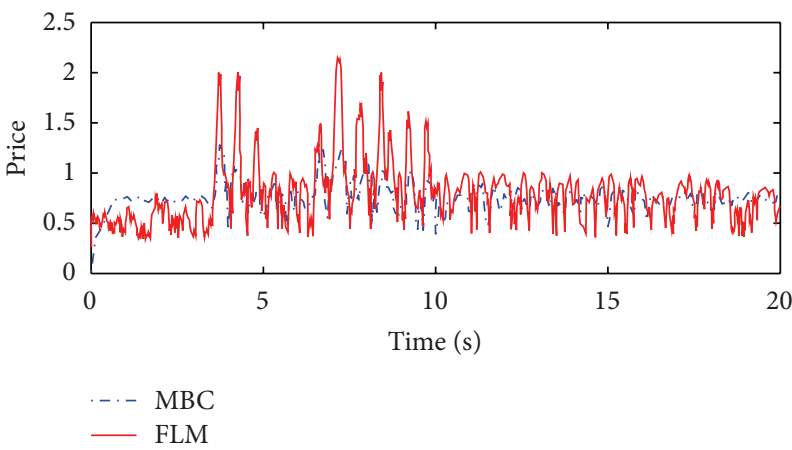

(a)

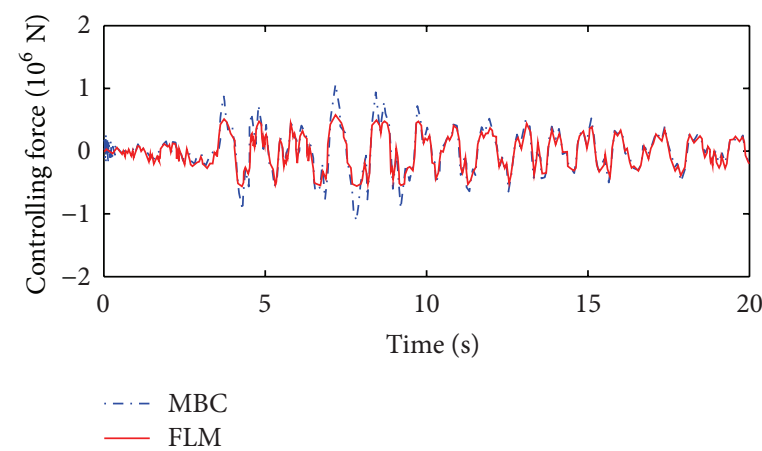

(b)

FIGURE 7: Responses of the structure under no. 2 earthquake record: (a) price time history; (b) control force time history.

was only sourced from the case under El Centro earthquake record.

\section{Summary and Conclusions}

Significant progress has gone towards developing a new control category, which has the highest performance on the robustness, uncertainty, and effectiveness in civil engineering. Although the MBC has capability of performing an effective control for structures, the complex solution of equilibrium price and poor robustness of the MBC limits its application in complex structures. As the artificial intelligence theory matures, the fuzzy logical method is introduced or incorporated in the structural control technology in recent years. Many problems, which are relatively difficult to answer using the traditional control method, were solved with various degrees through the smart control algorithms and technology. In this paper, the fuzzy logical method is incorporated in the $\mathrm{MBC}$ to simplify the $\mathrm{MBC}$ procedure and improve its performance through establishing a fuzzy 


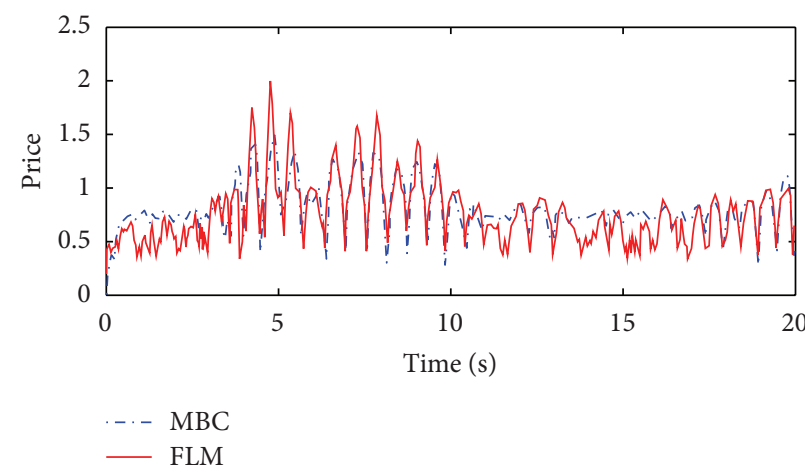

(a)

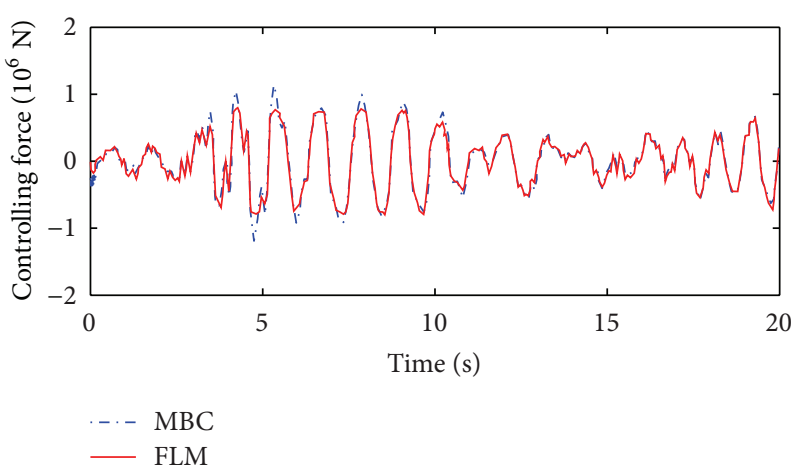

(b)

FIGURE 8: Responses of the structure under no. 3 earthquake record: (a) price time history; (b) control force time history.

rule based on a single-degree-of-freedom system under the earthquake. The results have shown that the fuzzy rule has ability of reducing the displacement and acceleration responses effectively similar to the $\mathrm{MBC}$ through comparing researches, and consuming computation time for the FLM is obviously saved. The present research implements a fuzzy theory model for use in the market-based control, which is a robust, efficient, and stable algorithm for conducting the structural vibration control.

\section{Acknowledgments}

Funding for authors was provided by the Science Fund for Creative Research Groups of the National Natural Science Foundation of China (Grant no. 51121005), the National Natural Science Foundation of China (Grant no. 51222806), and 973 Project (Grand no. 2011CB013605). The opinions, findings, and conclusions expressed in this paper are those of the authors and do not necessarily reflect the views of those acknowledged here.

\section{References}

[1] T. T. Soong, Active Structure Control Theory and Practice, Longman Scientific \& Technical, New York, NY, USA, 1990.

[2] L. Huo, G. Song, H. N. Li, and K. Grigoriadis, "Ho robust control design of active structural vibration suppression using an active mass damper," Smart Materials and Structures, vol. 17, no. 1, pp. 15-21, 2008.

[3] J. P. Ou, Structural Vibration Control-Active, Semi-Active and Smart Control, Science Press, Beijing, China, 2003.

[4] S. Clearwater, Market-Based Control: A Paradigm for Distributed Resource Allocation, World Scientific, Singapore, 1996.

[5] T. Alpcan, T. Başar, R. Srikant, and E. Altman, "CDMA uplink power control as a noncooperative game," in Proceedings of the 40th IEEE Conference on Decision and Control (CDC '01), pp. 197-202, Orlando, Fla, USA, December 2001.

[6] J. E. Hilland, R. R. Wessen, D. Porter, and R. S. Austin, "A market-based conflict resolution approach for satellite mission planning," IEEE Transactions on Engineering Management, vol. 48, no. 3, pp. 272-282, 2001.
[7] M. B. Dias and A. Stents, "A comparative study between centralized, market-based, and behavioral multi-robot coordination," in Proceedings of the IEEE/RSL International Conference on Intelligent Robots and Systems (IROS '03), pp. 2297-2303, Las Vegas, Nev, USA, October 2003.

[8] W. B. Jackson, C. Mochon, K. Van Schuylenbergh et al., "Distributed allocation using analog market wire computation and communication," in Proceedings of the 7th Mechatronics Forum International Conference, Atlanta, Ga, USA, September 2000.

[9] K. Prouskas, A. Patel, J. Pitt et al., "A multi-agent for intelligent network load control using a market-based approach," in Proceedings of the 4th International Conference on Multi Agent Systems (ICMAS '00), pp. 231-238, IEEE Computer Society, Boston, Mass, USA, 2000.

[10] J. P. Lynch and K. H. Law, "Market-based control of linear structural systems," Earthquake Engineering and Structural Dynamics, vol. 31, no. 10, pp. 1855-1877, 2002.

[11] L. Huo and H. Li, "Control law for market-based semi-active timed liquid column dampers," Chinese Journal of Applied Mechanics, vol. 1, pp. 71-75, 2005.

[12] Y. Li, Structural vibration control using MBC strategy [Masteral dissertation], Dalian University of Technology, Dalian, China, 2007.

[13] G. Li, Q. Liu, and H. N. Li, "Inelastic structural control based on MBC and FAM," Mathematical Problems in Engineering, vol. 2011, Article ID 460731, 18 pages, 2011.

[14] M. Aldawod, B. Samali, F. Naghdy, and K. C. S. Kwok, "Active control of along wind responce of tall building using a fuzzy controller," Engineering Structures, vol. 23, no. 11, pp. 1512-1522, 2001.

[15] A. S. Ahlawat and A. Ramaswamy, "Multiobjective optimal structural vibration control using fuzzy logic control system," Journal of Structural Engineering, vol. 127, no. 11, pp. 1330-1337, 2001.

[16] K. C. Schurter and P. N. Roschke, "Neuro-fuzzy control of structures using acceleration feedback," Smart Materials and Structures, vol. 10, no. 4, pp. 770-779, 2001.

[17] K.-S. Park, H.-M. Koh, and C.-W. Seo, "Independent modal space fuzzy control of earthquake-excited structures," Engineering Structures, vol. 26, no. 2, pp. 279-289, 2004.

[18] M. K. Bhardwaj and T. K. Datta, "Semiactive fuzzy control of the seismic response of building frames," Journal of Structural Engineering, vol. 132, no. 5, pp. 791-799, 2006. 
[19] H.-S. Kim and P. N. Roschke, "GA-fuzzy control of smart base isolated benchmark building using supervisory control technique," Advances in Engineering Software, vol. 38, no. 7, pp. 453-465, 2007.

[20] R. Guclu and H. Yazici, "Fuzzy logic control of a non-linear structural system against earthquake induced vibration," Journal of Vibration and Control, vol. 13, no. 11, pp. 1535-1551, 2007.

[21] S. M. Zahrai and A. Shafieezadeh, "Semi-active control of the wind-excited benchmark tall building using a fuzzy controller," Iranian Journal of Science and Technology B, vol. 33, no. 1, pp. 1-14, 2009.

[22] D. Zhao and H. Li, "Shaking table tests and analyses of semiactive fuzzy control for structural seismic reduction with a piezoelectric variable-friction damper," Smart Materials and Structures, vol. 19, no. 10, pp. 1-9, 2010.

[23] K. Yeh, "Seismic response control of sliding isolated buildings using adaptive fuzzy sliding mode control," International Journal of Physical Sciences, vol. 6, no. 20, pp. 4732-4738, 2011. 


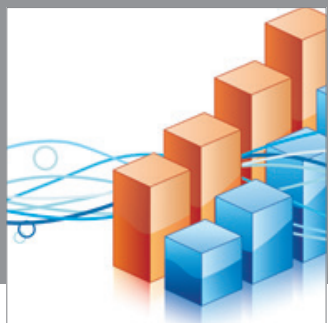

Advances in

Operations Research

mansans

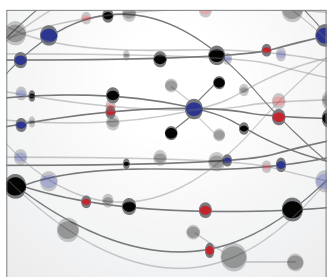

The Scientific World Journal
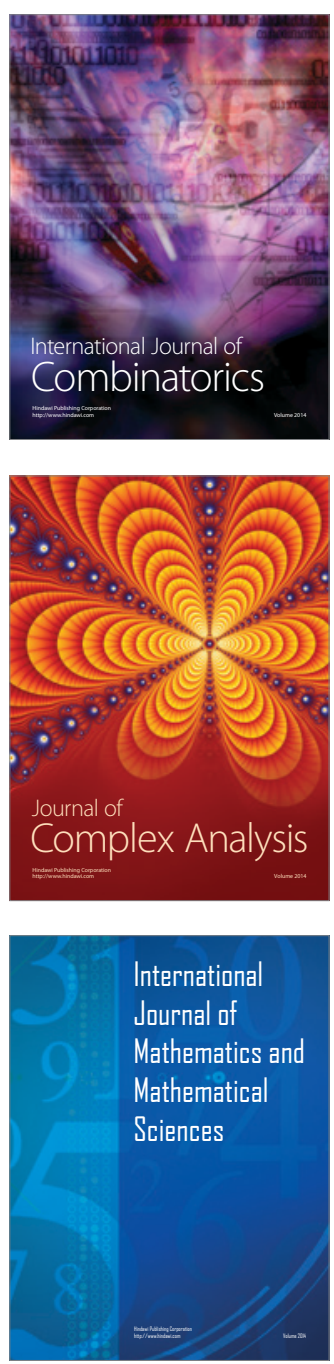
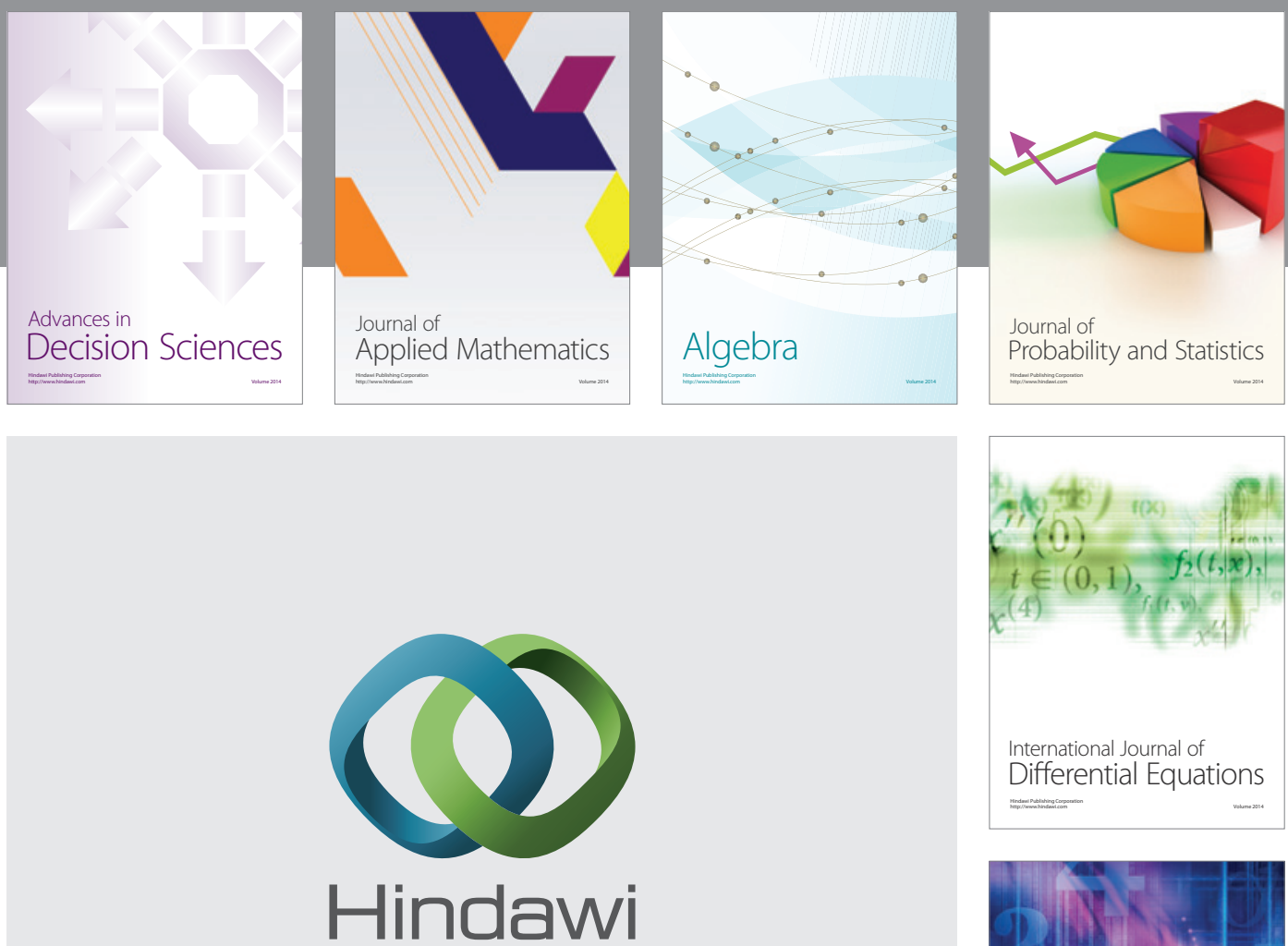

Submit your manuscripts at http://www.hindawi.com
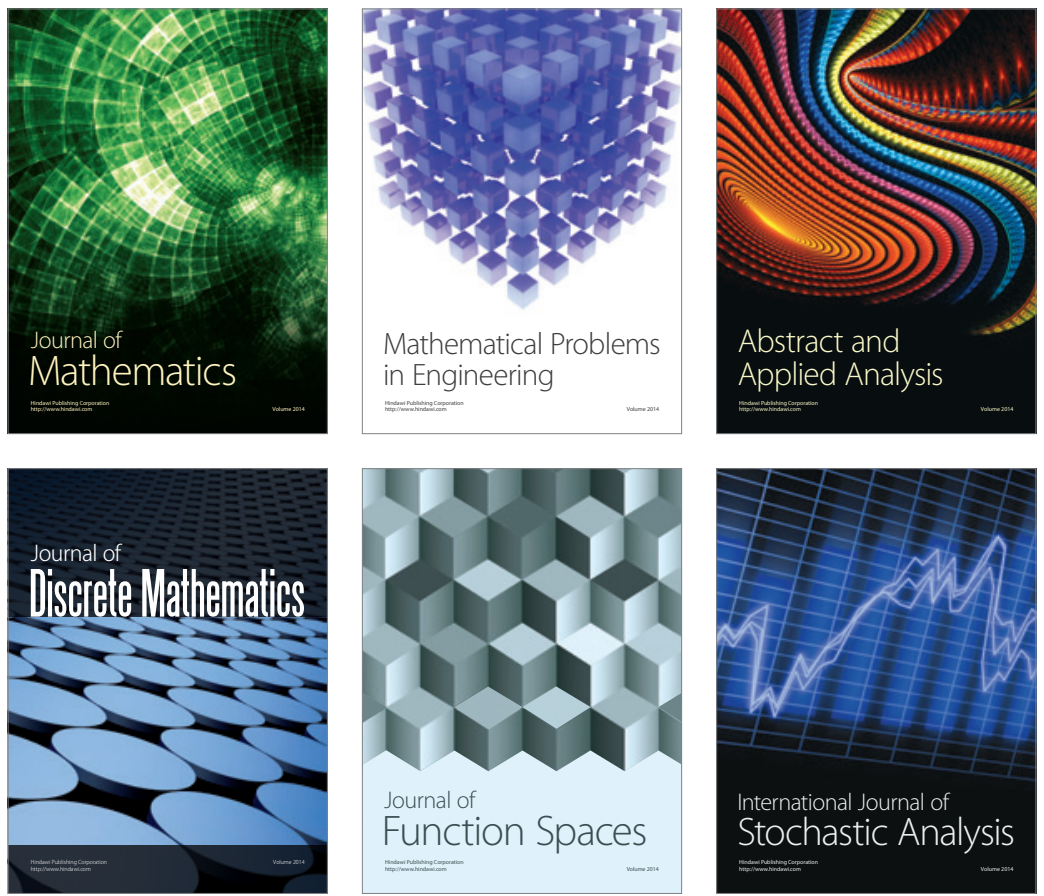

Journal of

Function Spaces

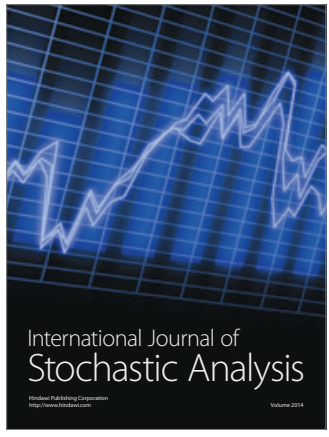

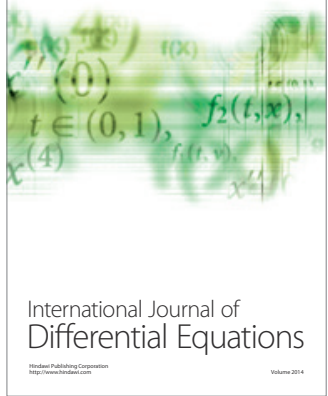
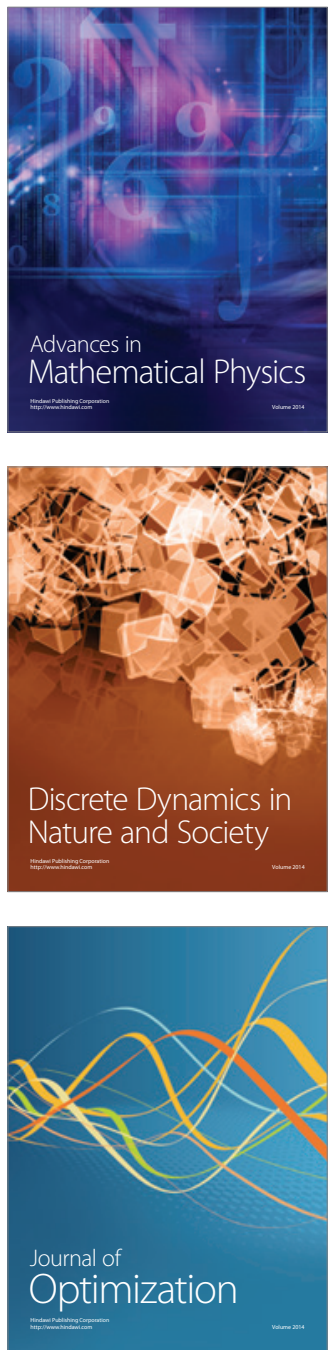